\title{
DISCRIMINAÇÃO RACIAL E DE GÊNERO EM DISCURSOS DE MULHERES NEGRAS COM ANEMIA FALCIFORME
}

\author{
Racial and gender discrmination on the discourses of black \\ women with sickle cell anemia \\ Discriminación racial y de género en discursos de mujeres negras
con anemia falciforme
}

Rosa Cândida Cordeiro ${ }^{1}$

SILVIA LÚCIA FERREIRA²

\section{RESUMO}

Estudo exploratório-descritivo com abordagem qualitativa, teve como objetivo identificar e descrever práticas de discriminação racial e de gênero nos serviços de saúde, referidas por mulheres negras com diagnóstico de anemia falciforme. Os dados foram coletados em Salvador/BA, em 2006, por meio de entrevista semiestruturada, gravada e transcrita. Para a análise dos dados foi utilizada a técnica do Discurso do Sujeito Coletivo. Os discursos construídos oferecem um conjunto de elementos que nos dão pistas de como o tratamento injusto, descortês e humilhante é um fenômeno naturalizado e revela de modo indireto a discriminação racial e de gênero nos serviços de saúde. Apresenta ainda situações que expõem as pessoas a constrangimentos e que atingem a dignidade humana.

Palavras-chave: Preconceito. Mulheres. Anemia Falciforme.

\begin{abstract}
This is an exploratory and descriptive study based on qualitative research. The objective of this study is to identify and describe gender and racial discrimination in the health service experienced by black women with sickle cell anemia diagnosis. The data were collected in Salvador- BA, in Brazil, in 2006 through semistructured interviews that were recorded and transcribed. For the data analysis the used technique was the Collective Subject Discourse. The discourses offer to built a cluster of elements that illustrates how unfair, unkind and humiliating treatment. It is a naturalized phenomenon that indirectly reveals racial discrimination in the health service. The discourses also show situations in which people are exposed to embarrassing circumstances that affect human dignity.
\end{abstract}

Keywords: Prejudice. Women .Anemia, Sickle Cell

\section{Resumen}

Esta investigación exploratorio-descriptiva con abordaje cualitativa, tuvo como objetivo identificar y describir las prácticas de discriminación racial y de género en los servicios de salud, dicho por mujeres negras con anemia falciforme. Los datos fueran colectados en Salvador-BA-Brasil, el año 2006 a través de entrevista semi estructurada, grabada y transcrita. Para el análisis de los datos se utilizó la técnica del Discurso del Sujeto Colectivo. Los discursos construidos muestran un conjunto de factores que indican cómo el tratamiento injusto, descortés y humillante es un fenómeno naturalizado y revela de modo indirecto la discriminación racial y de género en los servicios de salud. Presenta aún situaciones que exponen las personas a constreñimiento e que atingen a la dignidad humana.

Palabras clave: Perjuicio. Mujeres. Anemia de células falciformes

${ }^{1}$ Enfermeira Sanitarista da Prefeitura Municipal de Salvador. Mestra em Enfermagem pela Escola de Enfermagem da Universidade Federal da Bahia (UFBA). Brasil. E-mail: rosa.candida@yahoo.com.br, ${ }^{2}$ Professora Doutora do Departamento de Enfermagem Comunitária. Professora Permanente do Programa de Pós-Graduação em Enfermagem da Escola de Enfermagem e do Programa de Pós-Graduação em Estudos Interdisciplinares sobre Mulheres, Gênero e Feminismo FFCH/NEIM/Universidade Federal da Bahia (UFBA). Pesquisadora do GEM- Grupo de Estudos sobre Saúde da Mulher e do NEIM- Núcleo de Estudos Interdisciplinares sobre a Mulher. Brasil. E-mail: silvialf@ufba.br 


\section{INTRODUÇÃO}

0 preconceito e a discriminação racial têm sido objeto de análise pelos cientistas sociais no Brasil, especialmente para pensar o impacto que estes fenômenos produzem na dinâmica das relações sociais. Com relação ao campo da saúde, os estudos são mais recentes e, sobretudo, mais difíceis de serem realizados, não apenas pela dificuldade de pesquisar o intrincado campo das relações sociais (clientela/profissionais de saúde; clientela/serviços de saúde), mas também na aplicação de metodologias adequadas que dêem conta de desvendar e de revelar discriminação, racismo e outros processos que produzem exclusão social.

As modalidades pelas as quais a discriminação se expressa na área de saúde nunca são diretas e evidentes, são envolvidas nas teias das relaç̃̃es sociais e econômicas que estruturam e determinam o processo saúde-doença, seja de seus determinantes diretos ou indiretos.

É fácil constatar que o acesso aos serviços de saúde varia para os diferentes grupos que compõem a população, com maior desvantagem para os negros, e que os diferentes níveis de reprodução da desigualdade social e de saúde têm suas origens fortemente fincadas no gênero, raça e classe.

Como essas categorias sociais se entrecruzam e marcam a vida das pessoas, também alargam e aprofundam o entendimento do eixo da exploração-dominação; "trata-se, portanto, de um processo de exploração-dominação baseado na articulação dessas três estruturas de organização social". Não se hierarquizam estas categorias. Do mesmo modo, os determinismos e as tipificações são afastados; ora a organização social de classe far-se-á predominantemente, ora a de gênero, ora a étnico-racial, ou as três igualmente 1 .

Na sociedade brasileira, as distinções de gênero não podem ser compreendidas de forma adequada sem considerarmos a questão racial, pois pela articulação dessas categorias é que se encontram os determinantes da saúde, doença e morte da população ${ }^{1}$.

Neste sentido, ao optar neste estudo pela inclusão destas categorias (gênero, classe e raça), pudemos compreender melhor como as práticas de discriminação se consubstanciam em dificuldades de acesso aos serviços de saúde das mulheres negras com anemia falciforme.

Para este estudo, a discriminação racial foi definida como tratamento diferenciado em função da raça, que coloca em desvantagem grupos raciais específicos. Discriminação racial significa qualquer distinção, exclusão, restrição ou preferência, baseados em raça, cor, descendência ou origem nacional ou étnica, que tenha por objeto ou efeito anular ou restringir o reconhecimento, o gozo ou o exercício em condições de igualdades fundamentais no domínio político, econômico, social e cultural ou em qualquer outro domínio na vida pública? ${ }^{2}$.

A discriminação racial está frequentemente associada à discriminação de gênero: as mulheres negras têm menos acesso à educação e são inseridas nas posiç̃̃es menos qualificadas do mercado de trabalho. Estas condições se refletem na ausência de informações, de conhecimento e de acesso aos serviços de saúde.

Alguns dados são importantes para entender esta realidade: a esperança de vida para as mulheres negras é de 66 anos, enquanto para as mulheres brancas é de 71 anos. A taxa de analfabetismo entre as mulheres negras é o dobro em relação às mulheres brancas. Elas são majoritariamente chefes de família sem cônjuge e com filhos, responsáveis pelo domicílio, portanto sobrecarregadas com o trabalho doméstico. Este perfil demonstra que a maioria das negras vive um processo de pauperização e exclusão social e estão abaixo da linha da pobreza $^{3}$.

0 Ministério da Saúde reconhece a existência de um potencial patogênico decorrente das discriminações. No caso das negras submetidas à discriminação racial, de gênero e de classe social, é maior o risco de comprometimento de sua identidade, da imagem corporal, de seu autoconceito e autoestima. Estas práticas de exclusão as impedem de desenvolverem estratégias positivas de enfrentamento, tornando maior o risco de comprometimento para sua saúde.

A consequência é também o menor acesso aos serviços de saúde de boa qualidade, à atenção ginecológica e à assistência obstétrica, e elas apresentam também maiores riscos de contrair e morrer de determinados grupos de doenças cujas causas são evitáveis ${ }^{3}$

Um estudo identifica que, além da inadequação encontrada no atendimento do pré-natal, a peregrinação em busca de atendimento foi de $31,8 \%$ entre as pretas, $28,8 \%$ entre as pardas e $18,5 \%$ entre as brancas. A anestesia foi amplamente utilizada para o parto vaginal em ambos os grupos; contudo, a proporção de puérperas que não teve acesso a este procedimento foi maior entre as pretas e pardas $-21,8 \% \mathrm{e}$ $16,4 \%$, respectivamente ${ }^{4}$.

Deste modo, é possível afirmar que a presença de práticas discriminatórias na atenção à saúde resulta na diminuição do acesso, na exclusão do atendimento adequado, influenciando a forma de nascer, viver e morrer das mulheres negras.

As práticas discriminatórias são indesejáveis e passíveis de punição nos termos da lei, entretanto a sub-representação de negros e indígenas entre cuidadores de nível superior e a falta de "habilidade" para o manejo de raça e etnia dificultam a identificação de estratégias individuais e coletivas de discriminação racial ou étnica, menos evidentes, porém eficientes ${ }^{5}$.

A pesquisa intitulada "A reprodução do racismo no setor saúde: sobrevivência e cidadania de risco", que constituiu o primeiro estudo no Brasil a expor e denunciar o racismo nas práticas de saúde, aponta que, embora o imaginário e as práticas discriminatórias nem sempre sejam percebidas de forma clara pelas pessoas, as falas das mulheres negras apresentam 0 
universo médico-hospitalar constituído de uma lógica discriminatória com raízes fundadas em concepções e mitos hegemônicos na sociedade brasileira, como os da democracia racial e do racismo cordial ${ }^{6}$.

0 quadro de exclusão da população negraé mais abrangente e determina 0 agravamento de suas condições de existência, levando principalmente à prematuridade dos óbitos tanto para homens como para mulheres. 0 perfil de mortalidade da população negra decorre da diferença no acesso e tratamento recebido, como no caso da anemia falciforme, cuja média de idade, 16-30 anos, contrasta-se com a média de 57 anos encontrada nos EUA.

0 impacto da anemia falciforme é significativo para a saúde das mulheres, sobretudo no período reprodutivo, pelos riscos de abortamentos, necrose da cabeça do fêmur e complicações no parto, principalmente por eclampsia. A doença em geral provoca uma gravidez de risco e com um índice mais alto de natimortos.

Como uma doença crônica negligenciada, o diagnóstico é tardio, e muitas vezes são comuns no cotidiano destas mulheres inúmeros atendimentos em serviços de emergência e frequentes internaç̃̃es que se constituem momentos de desequilibrio e de dificuldades. Além disso, o contexto dos serviços de saúde como espaço de manutenção e legitimação das desigualdades sociais e raciais permite que sejam criados mecanismos para práticas de discriminação racial e de gênero por meio de atitudes negativas, como conversa depreciativa ou tratamento injusto ou humilhante; na maioria das vezes as usuárias disfarçam para não compreendê-as e quase nunca exibem reação diante dessas práticas.

\section{OBJ ETIVO}

0 objetivo deste estudo foi identificar e descrever práticas de discriminação racial e de gênero nos serviços de saúde, referidas por mulheres negras com diagnóstico de anemia falciforme.

\section{METODOLOGIA}

Este estudo exploratório-descritivo, com abordagem qualitativa, teve como informantes dez mulheres negras residentes na periferia da cidade de Salvador com diagnóstico de anemia falciforme. Foram localizadas por meio de cadastro específico realizado em uma área de um distrito sanitário, a partir de agentes comunitários de saúde. A coleta de dados foi efetuada nos meses de agosto e setembro de 2006. Participaram mulheres que atenderam aos critérios de inclusão da pesquisa, a saber, que se autodeclararam pretas ou pardas, com diagnóstico de anemia falciforme e que aceitassem participar da pesquisa.

Nessa ocasião, enfatizamos a cada informante a importância de sua participação para êxito deste estudo; esclarecemos acerca dos objetivos da pesquisa, da forma de participação e da utilização das informações; também fizemos referência à liberdade de recusarem ou interromperem a participação no momento que assim desejassem, sem que tal decisão lhes causasse prejuízo de qualquer natureza. Garantimos, ainda, que, na apresentação dos resultados, seria mantido o anonimato das informantes. Finalmente, ressaltamos a disponibilidade dos pesquisadores para quaisquer esclarecimentos que se fizessem necessários. Assim, foram respeitados os preceitos éticos constantes na resolução 196/96 do Conselho Nacional de Saúde.

Para coleta de dados, realizamos entrevistas que foram gravadas e transcritas na íntegra. 0 roteiro da entrevista foi adaptado de outros estudos ${ }^{7-8}$ que tinham como sujeitos mulheres e homens negros e brancos. 0 roteiro foi composto por questões abertas referentes ao acesso aos serviços de saúde, à vivência de tratamento injusto, descortês ou humilhante e à conversa depreciativa identificada pelas mulheres quando procuraram o atendimento nos serviços de saúde, bem como às reações diante dessas vivências.

Para a análise dos dados, foi utilizada a técnica do Discurso do Sujeito Coletivo (DSC), pois permite representar o pensamento de uma coletividade, agregando num só discursosíntese conteúdo discursivo de sentido semelhante emitido por pessoas distintas ${ }^{9}$.

Foram construídas as expressões-chave a partir de transcrições literais de partes dos depoimentos, que permitem o resgate do que é essencial no conteúdo discursivo dos segmentos em que se divide o depoimento. A ideia centralde um discurso pode ser entendida como a(s) afirmação(ões) que permite $(\mathrm{m})$ traduzir o essencial do conteúdo discursivo explicitado pelos sujeitos em seus depoimentos; o discurso do sujeito coletivo é a reconstrução com pedaços de discursos individuais, de tantos discursos-síntese quantos forem necessários, para expressar um dado modo de pensar ou de representação sobre o fenômeno. Os discursos foram agrupados por tema abordado, que corresponde, basicamente, ao objetivo proposto. A cada DSC foi associada a uma ideia central correspondente para que, dessa forma, fosse possível analisar os depoimentos colhidos.

\section{RESULTADOS E DISCUSSÃO}

Apresentam-se a seguir os três discursos (DSC) e as ideias centrais que configuram o quadro de discriminação apontado nos discursos das mulheres. Os discursos apontam a evidência de práticas de saúde impregnadas de poder sobre o corpo feminino, a fala das mulheres sobre as conversas depreciativas na qual a linguagem é apresentada como capaz de denunciar uma significação depreciativa explícita, apontando a discriminação de forma clara. A palavra acusa uma oposição de sentidos, que se revela irônica e mordaz, ou ainda opera por um jogo de transferência de vocabulários numa situação em que o conteúdo pode ser associado à discriminação. Apresenta ainda a reação das mulheres diante do tratamento injusto e da conversa depreciativa. Apesar de autorrelatos de discriminação 
racial darem pistas de como esta dificulta o acesso e a permanência nos serviços de saúde, a opressão e a internalização da discriminação impedem que estas mulheres denunciem sua existência.

\section{Ideia Central - A discriminação é construída a partir de múltiplas faces: ser mulher, ser pobre, ser negra e ter anemia falciforme}

Em relação à construção da discriminação sofrida nos serviços de saúde, as mulheres a associaram ao fato de serem mulheres, negras e pobres. 0 discurso reúne a complexidade das situações em que as mulheres apontam a existência da discriminação racial na sociedade, inclusive nos serviços de saúde.

0 discurso afirma a existência da discriminação e vai tomando formas até colocar o racismo como um fenômeno presente, sendo permeado por situações que reafirmam como acontece a exclusão e a restrição ao acesso nos serviços de saúde para essas mulheres.

Eu acho que a sociedade em geral tem discriminação. Às vezes dizem assim: você sabe que essa doença só existe na população negra. Cuidado, se cuide é uma doença perigosa. Eu vejo sempre as pessoas falando, comentado que quem tem essa anemia são as pessoas da cor preta. Ë o pessoal mais escuro que tem, porque os claros são difíceis de pegar. Então sempre eu vejo alguém comentando. Sempre sofre mais quem é mais escura. E tem gente que tem racismo até hoje. Eu tive alguns momentos ruins e tenho até hoje, por falta de orientação médica; as enfermeiras estão de mau humor ou não sabem cuidar, ou não sabem o que é que a pessoa sente ali de verdade. Eu não gosto nem de falar, porque dá vontade de chorar. Sempre a gente acha que é discriminada. Eu me considero discriminada. (DIS 1)

A discriminação assume diversas formas. Pode ser direta, quando é claramente expressa, com recurso a regras e códigos que estabelecem distinções e preferências que propiciam a exclusão explícita de indivíduos dos segmentos sociais.

A depreciação e a rejeição estão presentes no discurso dessas mulheres, de forma sutil ou explícita, e são barreiras para o acesso e permanência nos serviços de saúde. São manifestações explícitas de discriminação racial reiterada na percepção de que está presente não apenas nos serviços de saúde.

Existe um sistema de valores que atua ao nível das atitudes e dos discursos que estimula a igualdade e a harmonia racial entre nós, chegando mesmo a afirmar que não existe preconceito e discriminação. Mas, como observamos no discurso, esse sistema de valores não atua com a mesma eficiência quando analisamos o comportamento racial que se apresenta no sistema das relações sociais concretas em que ocorre à discriminação.

0 discurso apresenta o preconceito, a discriminação e o racismo como práticas presentes nas instituições de saúde, e talvez a capacidade de identificá-los esteja associado à proximidade dessas mulheres com esses fenômenos e à aplicabilidade em situações concretas do cotidiano desses sujeitos.

Essas mulheres referiram nos depoimentos que muitas vezes são preteridas no internamento, permanecendo nas emergências esperando vaga, assistindo outros pacientes serem internados.

Todas as mulheres entrevistadas encontravam-se abaixo da linha da pobreza e com escolaridade entre primário completo e incompleto. Estes achados são compatíveis com outros estudos que apontam o dobro da taxa de analfabetismo, quando comparada com a das mulheres brancas. Esta também é uma das razões apontadas por estes estudos que leva essas mulheres terem menor acesso aos serviços de saúde de boa qualidade, 0 que resulta em maior vulnerabilidade para contrair e morrer de determinadas doenças ${ }^{10}$.

Nos discursos, identificam-se práticas de discriminação racial por meio dos comportamentos dos profissionais de saúde, muitas vezes pela expressão facial quando se apresenta para o atendimento uma mulher magra e com pele escura. Fica evidenciado como se produz sofrimento a partir do lugar ocupado por negros e brancos na sociedade. Esta dimensão do sofrimento, invisibilizado, não é compartilhado pelo coletivo, mas por cada pessoa atendida. Cada uma experimenta uma forma de sofrimento pela humilhação, vergonha, falta de reconhecimento como ser humano, e sua reação se expressa pelo choro e com grande interferência no processo de adoecimento dos sujeitos ${ }^{11}$.

Portanto, elas participam de dinâmicas nas instituições de saúde que lhes depreciam e invalidam a importância dos seus códigos sociais e culturais, desqualificando as experiências vividas. A lógica de depreciar e invalidar o que essas mulheres dizem como se não fosse uma verdade leva ao sentimento de desvalorização e diminuição. A instituição de saúde participa desse processo de exclusão e o torna inaudível: nada que se fala é levado a sério ou acreditado como verdade, há um silencio geral, o que pode ser denominado "lógica da invisibilidade do sofrimento" 12 .

Nesse sentido, o desafio de constituir a assistência à saúde baseada nos direitos humanos, com ênfase na subjetividade e que considere as singularidades, nos parece ser um caminho para consolidação de um modelo de atenção à saúde que possa atender as especificidades de todas as mulheres.

\section{Ideia Central - As falas e os silêncios dos profissionais são expressões de uma linguagem depreciativa e discriminatória}

Ao se reportarem ao tema, as entrevistadas apontaram que, nos serviços de saúde, frequentemente ouvem conversas depreciativas a seu respeito, destacaram uma avaliação do atendimento recebido nos serviços de saúde, com relatos ricos em detalhes, que demonstram o conhecimento dos serviços utilizados, diferenciando características do atendimento que 
consideram de qualidade e geradoras de satisfação daquelas que, ao contrário, causam insatisfação.

Apontaram ainda a presença de palavras, expressões com significados explícitos de discriminação e conversas depreciativas durante 0 atendimento. 0 discurso refere-se ao atendimento de enfermagem hospitalar como um atendimento baseado no modelo biomédico, que desconsidera o conhecimento sobre a clientela dificultando assim o diagnóstico e tratamento dos problemas de saúde, apresentando indícios do trabalho de enfermagem voltado para o modelo funcional dividido em tarefas e procedimentos, conforme pode ser observado pelo DSC.

Uma vez eu estava no hospital, e a enfermeira, nem pra dizer que era branca,tinha preconceito por eu ser preta e com anemia falciforme. Ela era bem mais escura que eu, e por isso eu não esperava preconceito. Ela estava atendendo muito bem, aí a outra amiga veio dizer: cuidado, é anemia falciforme, bota luva. Sabendo que é uma doença que não se pega, a gente já nasce, é hereditária. Então ela veio com aquela coisa como se fosse uma doença que poderia pegar nela, mesmo sem sangue, sem nada, eu achei isso um absurdo. (DIS 2)

Os discursos são, por vezes, portadores de uma significação depreciativa explícita, denunciando a discriminação de forma extremamente clara. Por vezes, a palavra acusa uma oposição de sentidos, que se revela irônica, ou ainda opera por um jogo de transferência de vocabulários de uma situação em que o conteúdo do estereótipo se associa à palavra. No caso, "falcêmica" pode estar sendo associado à "leucêmica" e ao significado desta patologia para os que são acometidos. Ao mesmo tempo a palavra "anêmica" para a portadora da anemia falciforme revela um estado de extrema fragilidade física, de falta de vontade para desenvolver as atividades cotidianas. 0 estereótipo "é uma visão simplificada e convincente de um indivíduo ou grupo, construída a partir de ideias negativas a respeito do outro, nascida da necessidade de promover e justificar a agressão"13:50. A classificação da cor da pele e características fenotípicas no Brasil acabou "operando e estabelecendo uma escala de valores pautadas na dinâmica dos relacionamentos sociais calcados em estereótipos e incluem tanto as pessoas consideradas negras como as consideradas mestiças" 14:32.

Neste sentido, as palavras e os nomes que constroem a realidade social são tanto alvo quanto fruto de uma luta política, o que faz com que possamos definir o real como um campo de lutas para definir o que é real, atribuindo à representação do mundo um ato de magia social, pelo qual as palavras têm 0 poder de fazer existir ou inexistir aquilo que existe ${ }^{15}$.

Os profissionais de saúde apresentam resistência a uma atenção centrada na pessoa, já que não foram preparados pelas universidades para atuar de forma diferenciada, respeitando a subjetividade e autonomia do cliente. Os modelos assistenciais que privilegiam um acompanhamento mais humanizado, voltado para o atendimento individualizado, são geralmente preteridos para uma lógica voltada para a especialidade, para o uso indiscriminado de alta tecnologia.
A humanização e a qualidade da atenção implicam compartilhar saberes e reconhecer direitos, estabelecendo-se relações mais igualitárias entre sujeitos, mesmo que se apresentem distintos conforme suas condições raciais, étnicas, culturais, sociais e de gênero; estas premissas são colocadas na Política Nacional de Atenção Integral à Saúde da Mulher ${ }^{10}$.

É preciso também levar em consideração a necessidade da atenção humanizada de enfermagem, visto que o trabalho de enfermagem é parte da assistência à saúde prestada dentro da instituição hospitalar e está organizado num modelo de assistência para atender as necessidades individuais, voltados para a doença, com objetivos imediatos e executados em sua maioria por pessoal não qualificado.

0 cuidado de enfermagem, fragmentado em "técnicas" ou "tarefas", permite o desenvolvimento de uma prática funcional, visando economia de tempo e maior agilidade na execução do serviço. Dentro desse sistema, os cuidados a serem prestados aos pacientes são distribuídos entre os elementos da equipe de enfermagem que, supostamente, tenham competência técnica para executá-lo, visto que as tarefas são divididas por grau de complexidade.

Uma vez que as mulheres, em particular as entrevistadas, apresentam necessidades emocionais e sociais diferenciadas de serem ouvidas, compreendidas e apoiadas. Escutar o que essas mulheres têm a dizer talvez seja a melhor estratégia que o profissional de enfermagem tenha que desenvolver para ajudá-las ${ }^{12}$.

\section{Ideia Central - A naturalização da opressão e a banalização do sofrimento são expressões do tratamento injusto, descortês ou humilhante que promovem, ao mesmo tempo, a passividade, a tolerância e a invisibilidade das mulheres}

No DSC o tratamento injusto aparece associado ao preconceito e discriminação que sofrem as mulheres que têm anemia falciforme, nos serviços de saúde. 0 tratamento injusto além de gerar sofrimento promove ao mesmo tempo a passividade, a tolerância e a invisibilidade, conforme evidencia oDSC.

Eu nunca reclamei porque é aquela questão: a pessoa mal está aguentando andar, mal está falando, às vezes está sozinha; quando reclama de alguma coisa, geralmente eles te deixam lá de molho, jogada, e, se sabe que você reclamou é pior ainda, ruim, porque sabe que é anemia falciforme, já tem preconceito, pelo menos eu considero preconceito, eles tratam com preconceito por ter anemia falciforme. Se a gente reclamar é pior ainda, eles não atendem ou então eles atendem de qualquer jeito, maltratando.(DIS 3)

0 reconhecimento de serem discriminadas e vítimas de preconceito nos serviços de saúde aparece durante a entrevista, mostrando que essas mulheres se apercebem do fato, mas esta percepção não é suficiente para que elas registrem queixa do tratamento recebido. 
No discurso, as mulheres aceitam o tratamento injusto como fato normal, da vida, e por isso não reclamam. Chegam a falar que tem o direito de serem atendidas, ficam zangadas, aborrecidas, mas o medo e a intimidação as deixam caladas. A situação de dor, de descaso, o fato de estarem sozinhas e o medo de sofrerem retaliações após a queixa são colocados como empecilhos para procura da direção do serviço.

A discriminação se manifesta por ser uma doença que "acomete" mais a população negra e pela aparência magra das mulheres. Em relação ao contexto da discriminação, o espaço mais indicado foi o hospital, principalmente nas unidades de emergência, pois é por este caminho que mais rapidamente elas são atendidas quando acometidas por crises dolorosas. Nesses locais, a discriminação se traduz pela falta de orientação médica sobre a doença e o tratamento e muitas vezes por receberem medicamentos e cuidados que não são adequados ao diagnóstico. Relatam também o mau humor das enfermeiras, pois estas afirmam que elas são viciadas em medicamentos.

As mulheres atribuem o desencadeamento de atitudes discriminatórias tanto pela condição social quanto pela cor, mas também pelo fato de serem mulheres, terem anemia falciforme e chegarem ao serviço de saúde geralmente sozinhas. A discriminação racial experimentada pode ter grande impacto sobre suas vidas, gerando situações de estresse e enfermidades. Vivenciar situações de discriminação pode ser, por si só, um elemento desencadeador de problemas de saúde, principalmente quando se passa no contexto de um serviço de saúde.

\section{CONSIDERAÇÕES FINAIS}

Com a discriminação incorporada como habitus, sua manifestação assume diversas formas, podendo ser diretamente, com regras e códigos que estabelecem distinção e preferências que geram espaços de poder e proporcionam a exclusão explícita de vários segmentos sociais. Envolve ainda situações que expõem pessoas a constrangimentos, atingidas em sua dignidade humana.

Os profissionais de saúde são apresentados nos discursos como proprietários do saber e responsáveis por decidir toda terapêutica utilizada sem nenhuma possibilidade de questionamento e intervenção. E o tratamento injusto, descortês e humilhante aparece como um fenômeno naturalizado, revelando o modo indireto de discriminação racial nos serviços de saúde. Este é um espaço onde o preconceito e a discriminação racial está presente; isso não quer dizer que estejam explícitos em todos os momentos, mas adquirem uma forma hierárquica quando há um sentido de dominação por parte daqueles que se sentem superiores.

As falas e os silêncios dos profissionais são expressões de uma linguagem depreciativa e discriminatória, que está inserida num discurso silencioso, de tolerância com reservas, tendo capacidade de menosprezar e desvalorizar.
A naturalização da opressão e a banalização do sofrimento são expressões do tratamento injusto, descortês e humilhante que promovem ao mesmo tempo a passividade, a tolerância e a invisibilidade. Essa invisibilidade social também torna o sofrimento invisível diante da instituição e dos profissionais de saúde.

A discriminação varia com recorte de gênero e fornecem pistas sobre as diferentes experiências que cada mulher passa ao se defrontar com serviços e profissionais despreparados para promoção da igualdade.

Com base nos discursos analisados, concluímos que as mulheres entrevistadas estão posicionadas em um espaço onde as práticas de discriminação baseadas na cor/raça, classe e gênero se encontram, produzindo processos simultâneos e variados, porém danosos. Foi possível perceber que a discriminação racial e de gênero age com igual força tanto no acesso como na permanência dessas mulheres nos serviços de saúde, e que não está inserida apenas nas práticas individuais, mas faz parte das normas e rotinas institucionais.

Do ponto de vista institucional, tanto no âmbito das políticas, dos programas e das relações interpessoais que perpassam as práticas de saúde, identifica-se também a necessidade de mudanças para atender a esta realidade social. Algumas iniciativas, decorrentes de amplo processo de mobilização social, já podem ser apontada neste sentido: as conferências estaduais e nacionais dos diversos seguimentos, como saúde, mulheres e população negra, que resultaram em políticas nacionais. Os relatórios recomendam a transversalidade na construção de redes comprometidas e solidárias com a proteção da saúde estimulando a corresponsabilidade entre sujeitos e coletividade, isto é, preconiza uma série de propostas para a mudança das relações entre equipes, profissionais, gestores e usuários dos serviços. Definem também a importância da escuta, do acolhimento, da negociação e do diálogo para a produção do cuidado como fatores que possibilitam a democratização das relações, e ações de saúde planejadas de acordo com as necessidades reais das populações e dos indivíduos ${ }^{16}$.

A humanização é também a inclusão do(a) trabalhador(a) de saúde em um processo de valorização e educação permanente, sensibilizados(as) ao problema da violência intrafamiliar e à questão dos preconceitos (sexual, racial, religioso e outros) na hora da recepção e dos encaminhamentos que possam ser orientados pelo conceito de saúde que o SUS na constituição brasileira consolidou como conquista.

Podemos dizer que esta pesquisa também confirma a precária condição socioeconômica em que vivem as mulheres negras na cidade de Salvador, condições que têm o potencial de comprometer a saúde física, mental e social dessas mulheres e, portanto, influenciam na sua existência como seres humanos e interferem no processo saúde doença.

A Política Nacional de Saúde Integral da População Negra define o conjunto de princípios, diretrizes e objetivos voltados para a melhoria das condições de saúde desse segmento da 
população. Inclui ações de cuidado e atenção à saúde, bem como de gestão participativa, controle social, produção de conhecimento, formação e educação permanente de trabalhadores de saúde, visando à promoção da equidade em saúde da população negra ${ }^{17}$.

Sua implementação reafirma a universalidade, a integralidade e a equidade, requerendo uma abordagem integrada às rotinas dos serviços de saúde, desde que

\section{Referências}

1- Safiotti H. Rearticulando gênero e classe social. In: Costa ACB, organizadora. Uma questão de gênero. Rio de Janeiro (RJ): Fundação Carlos Chagas/Rosa dos Tempos; 1992. p.183-215.

2- Convenção Internacional sobre eliminação de todas as formas de discriminação racial; 1968.

3- Cruz ICF. Saúde da mulher negra: ações afirmativas para a mulher no período perinatal. Online Braz J Nurs 2006 abr: [citado 20 de out 2006]. Disponível em: http://www.uff.br/objnursing.

4- Leal MC, Gama SGNC, Cunha CB. Desigualdades raciais, sóciodemográficas e na assistência ao pré-natal e ao parto. Rev Saude Publica 2005 jan; 39 (1): 100-07.

5- Lopes F. Raça, saúde e vulnerabilidade. Bol Instituto de Saude 2003 dez; 31: 7-11.

6- Moreira D. Relatório do Encontro Nacional de Mulheres Negras. Belo Horizonte (MG): jul 2001.

7- Krieger N. Embodying inequality: a review of concepts, measures and methods for studying health-consequences of discrimination. Int J Health Services. 1999 Feb; 9(2): 295-352.

8- Cruz ICF. Diferenciais raciais no acesso e na qualidade do cuidado e assistência prestados aos portadores de hipertensão arterial. In: Lopes F, coordenador. Saúde da população negra no Brasil: contribuições para a promoção da eqüidade. Relatório final. Brasília (DF); 2004. observadas as especificidades da população negra e a sua diversidade quanto ao sexo, idade e situação socioeconômica.

Por fim, os discursos revelam iniquidades na atenção à saúde das mulheres negras, herdeiras das desigualdades resultantes das relações sociais e políticas pautadas por discriminações de natureza sexista e racial, com violação de direitos que dificultam o acesso à ascensão social e a condições dignas de saúde.

9- Lefevre F, Lefevre AMC, Teixeira JJV, organizadores. 0 discurso do sujeito coletivo: uma abordagem metodológica em pesquisa qualitativa. Caxias do Sul (RS): EDUCS; 2000.

10. Ministério da Saúde (BR). Política Nacional de Atenção Integral à Saúde da Mulher: princípios e diretrizes. Brasília (DF); 2004.

11-Carreteiro TC. Sofrimentos sociais em debate. Rev Psicol USP 2003 dez; 14(3): 57-72.

12- Batista CB, Silva LR. Sentimentos de mulheres soropositivas para HIV diante da impossibilidade de amamentar. Esc Anna Nery Rev Enferm 2007 jun; 11 (2): 268-75.

13- Silva AC. A discriminação do negro no livro didático. $2^{\mathrm{a}}$ ed. Salvador (BA): EdUFBA; 2004.

14- Ferreira RF. Uma história de lutas e vitórias: a construção da identidade de um afrodescendente brasileiro [tese de doutorado]. São Paulo (SP): USP; 1999.

15- Bourdieu P. Da regra às estratégias: a codificação. In:

Coisas ditas. Tradução de Cássia R. da Silveira e Denise Moreno Pegorim. São Paulo(SP): Brasiliense; 1990. p.77-107.

16- Ministério da Saúde (BR). Política Nacional de Humanização. Documento: base para gestores e trabalhadores do SUS. Brasília (DF); 2004.

17- Ministério da Saúde (BR). Política Nacional de Saúde Integral da População Negra. Brasília (DF); 2007. 